\title{
Should dispersers be fast learners? Modelling the role of cognition in dispersal syndromes
}

\author{
Jannis Liedtke $^{1}$ and Lutz Fromhage ${ }^{2}$ \\ ${ }^{1}$ University of Hamburg \\ ${ }^{2}$ University of Jyvaskyla Faculty of Mathematics and Science
}

March 29, 2021

\begin{abstract}
Both cognitive abilities and dispersal tendencies can vary strongly between individuals. Since cognitive abilities may help dealing with unknown circumstances it is conceivable that dispersers may rely more heavily on learning abilities than residents. However, cognitive abilities are costly and leaving a familiar place might result in losing the advantage of having learned to deal with local conditions. Thus, individuals which invested in learning to cope with local conditions may be more reluctant to leave their natal place. In order to disentangle the complex relationship between dispersal and learning abilities we implemented individual-based simulations. By allowing for developmental plasticity, individuals could either develop a 'resident' or 'dispersal' cognitive phenotype. In line with our expectations, the correlation between learning abilities and dispersal could take any direction, depending how much time individuals had to recoup their investment in cognition. Both, longevity and the timing of dispersal within lifecycles determine the time individuals have to recoup that investment and thus crucially influence this correlation. We therefore suggest that species' life-history will strongly impact the expected cognitive abilities of dispersers, relative to their resident conspecifics, and that cognitive abilities might be an integral part of dispersal syndromes.
\end{abstract}

\section{Hosted file}

MS Cognitive styles and dispersal_plasticity_25_03.pdf available at https://authorea.com/ users/404718/articles/515822-should-dispersers-be-fast-learners-modelling-the-role-ofcognition-in-dispersal-syndromes

\section{Hosted file}

Figure 1.pdf available at https://authorea.com/users/404718/articles/515822-shoulddispersers-be-fast-learners-modelling-the-role-of-cognition-in-dispersal-syndromes

\section{Hosted file}

Figure 2.pdf available at https://authorea.com/users/404718/articles/515822-shoulddispersers-be-fast-learners-modelling-the-role-of-cognition-in-dispersal-syndromes 